\title{
"Tive o desejo apenas de lhe dar todos os esclarecimentos que podia"
}

[ "I simply had the wish to clear all things up as best as I could"

Ricardo Gaiotto de Moraes ${ }^{\mathrm{I}}$

MORAES, Ricardo Gaiotto de. "Tive o desejo apenas de lhe dar todos os esclarecimentos que podia”. Revista do Instituto de Estudos Brasileiros, Brasil, n. 67, p. 255-262, ago. 2017.

DOI: http://dx.doi.org/Io.II6o6/issn.23I6-90IX.voi67p255-262

I Pontifícia Universidade Católica de Campinas (PUC-Campinas, SP, Brasil). 


\section{Cartas a Graco Silveira}

Os caminhos de Mário de Andrade e Graco Silveira² se cruzaram quando aquele era diretor do Departamento de Cultura de São Paulo. O professor Graco Silveira, então lente da Escola Normal de Itapetininga, interior do estado, recebeu um convite de Mário de Andrade para que colaborasse com uma comunicação no I Congresso de Língua Nacional Cantada, ocorrido em I937. Graco Silveira, em artigo publicado no jornal O Estado de S. Paulo, em II de abril de I970, seis meses antes de sua morte, atesta que as relações dele com Mário de Andrade, "a princípio formais, tornaram-se mais amistosas" depois do Congresso. Transcreve, no artigo, um trecho do convite de Mário de Andrade em carta de I9 de março de 1937.

Graco Silveira responde em I4 de abril, agradecendo o convite e descrevendo uma frase toada de uma cantiga que registrara em povoado isolado, na zona da Ribeira, às margens do rio Etá, sudeste do estado de São Paulo. Considerava tratar-se de uma "genuína música de viola". A anotação, além de textos publicados por Graco da Silveira no jornal O Estado de S. Paulo3, pareceu despertar em Mário de Andrade profundo interesse pelos conhecimentos em pesquisa de folclore do remetente.

O estudo sobre a fala dos moradores da região do Etá foi apresentado na comunicação "Alguns traços do dialeto caipira e do subdialeto da Ribeira", no I Congresso de Língua Nacional Cantada, transcrita nos Anais do evento4. No início do texto, Graco Silveira expressa estar em consonância com o objetivo do congresso de estabelecer um padrão de pronúncia para algumas expressões culturais brasileiras, ainda que considere a fala como um espaço de variação linguística.

Na comunicação, o autor elenca aspectos da pronúncia que ocorria na região da "Zona da Ribeira", baseando-se nas pesquisas de Amadeu Amaral, que então já publicara Dialeto caipira, Valdomiro Silveira, Cornélio Pires e Leôncio C. de Oliveira,

2 Graco Silveira Santos (São Roque, I900-Santos, I970), casado com Circe Prado da Silveira Santos, foi professor de Português, no Instituto de Educação Peixoto Gomide, em Itapetininga, filólogo, escritor e poeta.

3 Como o próprio Graco Silveira observa: "Alguns trabalhos nossos, publicados em O Estado, aguçaram-lhe o interesse folclórico pelo que nos propôs um estudo em conjunto" (O Estado de S. Paulo, II abr. I970, p. 52)

4 Conforme informa a carta de Mário de Andrade para Graco Silveira, I7 ago. I937. 
mas anotando as especificidades que observara na fala dos moradores da região. Nota, por exemplo, na prosódia, que "o fraseio dos ribeirinhos pode ser representado por uma espiral em direção oblíqua”.

Apesar do número aparentemente pequeno de cartas, o diálogo entre Mário de Andrade e Graco Silveira parece se estabelecer a partir de afinidades que incluem, além do interesse comum na pesquisa da forma de falar dos moradores da região do rio Etá, a concepção de língua sujeita a mudanças e variações. No artigo "A linguagem e a sociologia", Graco Silveira diferencia, por exemplo, o ensino de língua portuguesa, baseado em uma norma, da abordagem que qualifica como linguística, na qual estaria incluída a observação do fenômeno linguístico em si. A análise não se limitaria à fala, estudando, por exemplo, a colocação pronominal em Machado de Assis e destacando a diferença em relação àquela empregada em Portugal. Além de aceitar participar de um congresso que tinha por objetivo determinar um padrão para a língua nacional cantada, o que, de certa forma, denota aderência ao projeto encabeçado por Mário de Andrade, Graco Silveira também sugere a necessidade de o estudioso de literatura observar certo padrão da língua literária no Brasil, o que viria dois anos depois, em I939, a ser defendido por Mário de Andrade no rodapé "Vida literária”, do Diário de Notícias (RJ).

As cópias das cartas de Mário de Andrade chegaram até mim pela professora Alice E. D. Olivati quando nos encontramos numa disciplina ministrada por mim, em um curso de pós-graduação, em Itapeva. Agradeço à professora Alice pela grande generosidade. As cartas de Graco Silveira a Mário de Andrade encontram-se na Série Correspondência Mário de Andrade, no arquivo do escritor, no Instituto de Estudos Brasileiros da Universidade de São Paulo.

São Paulo, 22 de abril de I937.

\section{Meu caro confrade, sr. Graco Silveira}

Recebi sua carta com enorme prazer. Me permito, mais uma vez e com maior intimidade, insistir na sua presença ao nosso Congresso, pelo menos por duas ou três reuniões como o sr. me promete, e no envio de alguma comunicação sua. Ninguém melhor do que o sr. poderá representar a contribuição paulista aos Anais do Congresso. Já tenho o apoio das duas academias de letras, a brasileira e a paulista, bem como a presença certa do professor Sousa da Silveira e a colaboração entusiástica do professor Antenor Nascentes. Este com o poeta Manuel Bandeira estão organizando uma série de frases contendo os fonemas mais diferençados entre uma e outra regiões brasileiras. Com isso farei gravar em disco, por uma pessoa culta e outra inculta, todas as pronúncias regionais nossas. Como vê a parte linguística do Congresso já tem boa garantia de excelência, além de outras adesões importantes que estou esperando.

Quanto ao caso da melodia que o sr. colheu de caipiras do rio Etá, a honestidade não me permite lhe dar desde logo uma opinião mais minha, diante apenas de uma frase de

5 SILVEIRA, Graco. Alguns traços do dialeto caipira e do subdialeto da Ribeira. In: Anais do Primeiro Congresso da Língua Nacional Cantada (julho de I937). São Paulo: Departamento de Cultura, I938. p. 510.

6 SILVEIRA, Graco. "A língua do Brasil”. O Estado de S. Paulo, 27/II/I938, p. 9. 
quatro compassos. Pela observação dessa frase, não contendo ela mais do que um tetracorde, é difícil fixar qualquer opinião sobre caráter regional. O tetracorde é pequeno demais e obriga por isso à criação dum muito diminuto número de arabescos melódicos. Nas melodias muito primárias de qualquer país que use o semitom (e são quase todos), o sr. encontrará com certa facilidade frases muito semelhantes, como arabesco, à que me enviou. O que se pode afirmar da frase enviada é que ela, harmonicamente falando, é resolutamente tonal, empregando a tonalidade europeia por nós importada. E realmente entoando a frase, só posso observar a sua profunda pobreza melódica. Isso é constante, de-fato, na melódica caipira. Mas frequenta com muita abundância a melódica infantil ou aplicada à infância, de qualquer país europeu. E tenho realmente uma profunda sensação... infantil ao entoar a frase que o sr. me mandou. É curioso mesmo que o vício de tradições muito fixadas em mim, me obriga a entoar a frase em andamento bem mais rápido que o proposto na grafia enviada. O sr. indica "Lento", quando eu sinto um "Allegretto" ou pelo menos um “Andantino".

Deus me livre de dizer com isso que a sua indicação está errada. Pelo contrário: me sirvo disso para lhe dizer que esse elemento, essa lentidão é que traz alguma... alguma estranheza à frase e a liberta um pouco mais do seu vago internacionalismo tanto tonal como de arabesco melódico.

Por tudo isso não lhe poderei dar uma opinião mais a contento. Diz o sr. que a melodia lhe parece "genuína música de viola”. É bem possível, não só por caber perfeitamente dentro do conceito harmônico do instrumento, que é tonal, como porque o sr., conhecendo melhor a melodia completa, poderá melhormente identificá-la que eu.

Há porém um problema que me preocupa. A melodia foi cantada a duas vozes, formando terças ou sextas, ou foi cantada solisticamente? Pergunto isto porque a frase proposta não se assemelha às formas musicais mais geralmente usadas pelos caipiras com acompanhamento de viola. Estas "formas" ou coisa parecida são a moda, o cateretê, o cururu e a cana-verde. Todas estas formas são executadas quase obrigatoriamente a duas vozes em falso-bordão. Sucede porém que o caipira entoe toadas solísticas, acompanhadas de viola. As toadas rurais do Brasil, no geral se caracterizam pela fórmula poética, estrofe e refrão, mais raras nas danças que citei atrás e raríssimas na forma da moda. No caso da melodia colhida ser solista, talvez se trate mais propriamente duma toada. O sr. colheu os versos também? Os versos ajudam muito a reconhecer pra que forma pende um documento musical nosso.

Infelizmente o folclore músico nacional ainda tem essa agravante de variar demais. Tudo está muito incerto e a própria terminologia musical do nosso povo é duma hesitação pasmosa. A impressão que tenho, depois de muitos anos de estudo honesto e penoso, é que estamos em pleno período de formação tonal, formal e melódica. E ao mesmo tempo em pleno período de decadência, ocasionada principalmente pelo disco, pelo rádio, pelo piano, pelo nomadismo da nossa gente (o verso "Vou-me embora, vou-me embora" é um dos mais frequentes do nosso folclore) e da facilidade das comunicações do litoral.

Desculpe esta digressão longa e que não adianta senão melancolia. Tive o desejo apenas de lhe dar todos os esclarecimentos que podia.

A sua comunicação sobre os tabaréus do Etá me despertou porém uma ideia.

Já tenho aqui na Discoteca Pública, do Departamento, uma máquina portátil de gravação, que fiz adquirir justamente para dar aos estudos de folclore, etnografia e fonética nacional uma orientação mais estritamente científica. Por que não faríamos o Departamento e o sr. uma obra séria de colaboração, a respeito do folclore desses tabaréus? 
O sr. estudaria o folclore oral, anedotas, provérbios, poética, superstições, medicina, linguística e o Departamento gravaria as músicas, transcreveria as peças colhidas, e as estudaria bem como aos instrumentos e colheria objetos de interesse folclórico. E de todo esse trabalho faríamos uma comunicação longa e pormenorizada, que seria publicada na Revista do Arquivo, com separata.

Em qualquer caso eu estaria disposto a gravar as cantigas desses caipiras, caso a viagem não seja muito árdua, pois o transporte da máquina e seus dois funcionários exige dois automóveis. Peço-lhe pois os esclarecimentos necessários sobre a viagem de Itapetininga ao Etá.

Muito cordialmente

Mário de Andrade

Carta datada: “São Paulo, 22 de abril de I937", datiloscrito; autógrafo; papel timbrado: "Prefeitura do Municipio de S. Paulo/ Departamento Municipal de Cultura”. Fotocópia.

São Paulo, I6 de junho de I937.

Meu caro prof. Graco Silveira.

Recebi sua carta com certo atraso, ontem. Telegrafo-lhe hoje pedindo se possível o adiamento da nossa court d'amour de violeiros famanados, e agora lhe explico a razão. Em fins de maio fui nomeado pelo Ministério da Educação, apesar de duas recusas preliminares, "assistente técnico" do Serviço de Patrimônio Histórico e Artístico Nacional, e logo me punham à disposição uma verbinha de oito contos, correspondente ao trimestre abril-julho, com incumbência de fazer um recenseamento perfunctório do Estado quanto à arquitetura colonial, e os reparos na igrejinha de S. Miguel. Isso me obriga a aproveitar os dias 23 e 24 pra ir a S. Luís do Paraitinga e Ubatuba, conforme plano traçado, que implica no momento apenas o vale do Paraíba e litoral norte, mais não posso fazer. E não posso fazer porque esse trabalho preliminar tem de ser apresentado nos primeiros dias de julho e conjuntamente à prestação de contas, que assim determina a burocracia federal!

Assim, se a 23 estarei por outras bandas, já a 30 não poderei mais fazer viagens de tombamento, meu trabalho estará provavelmente concluído ou por concluir e poderei viajar pra Taquaral. Se lhe for possível arranjar pra 29 a festa, muito que bem, se não for possível, durante o Congresso em que terei a alegria de lhe apertar a mão aqui, combinaremos novo plano futuro, o que dará no mesmo. Muitíssimo obrigado por tudo, e creia-me seu

adm ${ }^{\text {or }}$ e amigo,

Mário de Andrade

Carta datada: “S. Paulo, I6-VI-I937”, datiloscrito; autógrafo; I folha. Fotocópia. 
São Paulo, I7 de agosto de I937.

Ilmo. Sr.

Graco Silveira,

Itapetininga

Esta Diretoria vem expressar a V.S. os seus melhores agradecimentos pela sua preciosa colaboração para o Congresso da Língua Nacional Cantada, com a apresentação de um interessante trabalho, que foi relatado em sessão e que será publicado nos Anais do Congresso já em elaboração, dos quais esta Diretoria terá o prazer de lhe enviar um exemplar.

Aproveitando-se do ensejo que se lhe apresenta, esta Diretoria junta as suas

Cordiais saudações

Mário de Andrade

Diretor.

Caixa Postal, 2867

S. Paulo

Carta datada: “São Paulo, I7 de agosto de I937", datiloscrito; papel timbrado: "Prefeitura do Municipio de S. Paulo/ Departamento Municipal de Cultura"; I folha. Fotocópia.

São Paulo, I3 de outubro de I937.

Meu caro Graco Silveira.

A Oneyda Alvarenga ainda não voltou das suas férias epitalâmicas, e por isso nada posso combinar, por enquanto, quanto à nossa viagem.

E sua saúde? Voltou integralmente?

Esta é para lhe pedir umas indicações. Poderia o sr. com o que sabe me organizar uma pequena lista cronológica de festas tradicionais populares ou popularizadas, tanto profanas como religiosas aí da zona, incluindo de outras zonas o que por acaso souber? A Soc. de Etnografia e Folclore está organizando para divulgação e uso um calendário de festas mais ou menos fixas, congados, cateretês, são-joões etc. em que se possa estudar povo.

Precisaria disso, se possível, até o dia 25 deste, para ler suas indicações em reunião da Soc.

Com a melhor amizade grata

do

Mário de Andrade

Carta datada: "S. Paulo I3-IO-37", autógrafo; papel timbrado: "Prefeitura do Municipio de S. Paulo/ Departamento Cultura”; I folha. Fotocópia. 
São Paulo, novembro de I937.

Ilmo. Sr.

Graco da Silveira

Rua Campos Salles, 2I

Itapetininga

O Departamento de Cultura está interessado em recensear, para catalogação dos tesouros existentes no Estado de São Paulo, todas as coleções particulares, de qualquer gênero, feitas pelos cultos paulistas.

Vem, nesse intuito, solicitar de V. S. a grande gentileza de lhe indicar qual a pessoa ou pessoas de seu conhecimento que colecionam obras de arte, objetos de arte, iconografia nacional e estrangeira, etnografia, folclore, moedas, selos, etc.

Pessoas há também que, sem serem propriamente colecionadores, guardam consigo obras de grande valor histórico, artístico ou documental. Seria também grande favor indicar essas pessoas.

Caso V.S. se disponha a favorecer-nos com sua resposta, esta deverá ser endereçada ao Departamento de Cultura, Diretoria, rua da Cantareira, 2I6, São Paulo.

É inútil dizer quão preciosa será a colaboração de V.S. neste caso, contribuindo desse modo para melhor ordem e sistema na conservação documentária dos tesouros de nossa terra.

Certa de ser atendida em seu apelo, esta Diretoria apresenta a V.S. as suas mui cordiais saudações.

Mário de Andrade

Diretor

N.B. Para melhor coordenação dos nossos trabalhos, solicitamos em sua resposta que a cada nome de colecionador ou pessoa possuidora de obras valiosas que indicar, seja mencionado também o gênero da coleção ou das coleções que possui e, se possível, a residência.

Carta datada: "São Paulo, novembro de I937", datiloscrito; papel timbrado: "Prefeitura do Municipio de S. Paulo/ Departamento Municipal de Cultura”; Nota do destinatário: “Resp. em I6.I2.37”. Fotocópia.

SOBRE O AUTOR

RICARDO GAIOTTO DE MORAES é doutor em

Teoria e História Literária pela Universidade

Estadual de Campinas (Unicamp) e professor do

mestrado em Linguagens, Mídia e Artes (Limiar) e

da Faculdade de Letras da Pontifícia Universidade

Católica de Campinas (PUC-Campinas).

E-mail:rgaiotto@gmail.com 


\section{REFERÊNCIAS BIBLIOGRÁFICAS}

SILVEIRA, Graco. "A língua do Brasil”. O Estado de S. Paulo, 27/II/1938, p. 9.

. Alguns traços do dialeto caipira e do subdialeto da Ribeira. In: Anais do Primeiro Congresso da Língua

Nacional Cantada (julho de I937). São Paulo: Departamento de Cultura, I938. p. 5 IO. 